PUBLIC ADMINISTRATION AND DEVELOPMENT

Public Admin. Dev. 25, 437-443 (2005)

Published online in Wiley InterScience

(www.interscience.wiley.com) DOI: 10.1002/pad.391

\title{
ON TWINNING: - THE IMPACT OF NAMING AN EU ACCESSION PROGRAMME ON THE EFFECTIVE IMPLEMENTATION OF ITS PROJECTS.
}

\author{
STEVEN O'CONNOR AND ROBERT KOWALSKI* \\ Centre for International Development and Training, University of Wolverhampton, Wolverhampton, UK
}

\begin{abstract}
SUMMARY
The introduction of the Twinning instrument as its principal institution-building mechanism in countries applying to join the European Union saw the appearance of a vocabulary very much at divergence with the language associated with other 'Technical Assistance' programmes. The arbitrary and connotational character of this heavily metaphorical terminology has differentiated Twinning from other programmes in the minds of those involved in the programme. At the same time, however, it has also resulted in a measure of ambiguity and confusion among project 'partners' - principally over their roles and responsibilities. This problem could be overcome by targeting any one of the three points in Peirce's semiotic model: by changing the signs of twinning; by re-attuning the users' interpretants; or by bringing the object, the Twinning programme itself, closer to how the signs of twinning are actually perceived and understood.
\end{abstract}

KEY WORDS - EU Programmes; metaphors; technical assistance; terminology; twinning projects

\section{INTRODUCTION}

In 1998 the European Commission (EC) launched a programme known as institutional Twinning, or more commonly, Twinning. The reasons behind initiating this new programme lay in a desire on the part of the Commission to improve the impact of Phare, its programme of financial and technical assistance to 10 countries of central and eastern Europe ${ }^{1}$ that had formally applied to join the European Union (EU) in the early 1990s, and a dissatisfaction with the results that had been achieved hitherto using 'traditional' consultancy-led technical assistance (TA) projects (Birker et al., 2000). The idea was a relatively simple one - bring together civil servants and sectoral experts from existing EU member states and their Phare country counterparts within the framework of a one or two-year project to exchange experience on an issue of common relevance. The ultimate objective of this interaction was to effect a pre-defined change within the Phare country administration that would bring it in line with the EU's legal code, the acquis communitaire, and thus closer to EU membership.

This article will not have as its central theme the successes or shortcomings of this initiative, which are documented elsewhere. ${ }^{2}$ Instead it will focus its attention on the terminology that has accompanied the introduction of this major EU initiative and examine how it is understood by a range of people with varying backgrounds and levels of knowledge of EU programmes, analyse how this term elicits the responses that it does, compare these findings against some concrete experiences of Twinning in practice and see what has resulted from the use of such terminology.

\footnotetext{
* Correspondence to R Kowalski, Centre for International Development and Training, University of Wolverhampton, Telford Campus, Priorslee, Telford TF2 9NT, UK. e-mail r.Kowalski@wlv.ac.uk

${ }^{1}$ Estonia, Latvia, Lithuania, Poland, Czech Republic, Slovakia, Hungary, Slovenia, Romania, Bulgaria

${ }^{2}$ See http://europa.eu.int/comm/enlargement/pas/twinning/pdf/assesm july.pdf and http://europa.eu.int/comm/enlargement/phare_evaluation_reports_interim.htm for evaluations of the Phare twinning instrument
} 


\section{SOME DEFINITIONS}

A common usage of the word twin suggests a matched, fraternal or parallel relationship of counterparts, and of the word adviser as somebody who counsels, suggests and informs. Interestingly, as we shall see later, Twinning seldom turns out as a matched, parallel or even equal relationship, whilst the adviser spends little time actually advising.

\section{SURVEY OF RESPONSES}

To test how the words twinning, adviser and another term, technical assistance, can be understood in various ways, a small survey with a selection of people from different backgrounds (both lay people and experts such as a British Diplomat responsible for EU affairs at the UK Embassy in the Czech Republic and covering the Twinning portfolio there; a former programme manager for the European Social Fund at the Lithuanian Government HRD Agency, having extensive knowledge of EU programmes and project work; Pre-Accession Adviser, Austria, having extensive knowledge of Twinning system and EU affairs) was conducted to get their responses to these trigger words. Some knew nothing about the EU or its Twinning programme, some knew something about projects generally, while others were well acquainted with the concept of Twinning and its associated terminology. The following questions were asked:

- What do you understand by the word twinning?

- What do you understand by the term technical assistance?

- What do you understand by the word adviser?

- Is there a difference between a manager and an adviser, and if so what is it?

Results indicated that those who knew nothing about the EU programme and had no contact with projects as such associated twinning with two entities that are the same, similar or equal, which have shared characteristics (by birth, interest). Those with some 'technical' concept of twinning mentioned town twinning, an initiative widely practiced in Europe of linking two (or more) towns in some kind of formal but non-binding, mutual relationship. ${ }^{3}$ Among those who understood the concept of twinning in an EU context, the responses eschewed the more 'naturalistic' definitions (i.e. siblings, similarities etc) and emphasised linkage, interaction, transfer of know-how and, of course, the Twinning programme itself.

When confronted with the term technical assistance, those with no prior knowledge of projects or the EU were unable to give any related response. By contrast, those with project experience were able to describe fairly explicitly their understanding of this term.

The word adviser elicited a more uniform response, with the emphasis on expertise, experience, and concepts of guidance and influence. Likewise, the response to the final question provoked similarly expressed answers - that there is a significant difference and that a manager can also advise, but an adviser is not there to manage.

\section{THEORETICAL ANALYSIS}

Peirce's model (Figure 1) defines communication as a triangular, two-way interaction between three components (Chandler, 2002). The top point of the triangle is the sign, the bottom-right corner is occupied by the object and the final corner by the interpretant. We will use this model to analyse the responses given in the survey. For example, those without experience or knowledge of the 'object' as a project interpret the sign twinning (italics are used to represent its function as a sign) in a 'naturalistic' way. By contrast, the response of the EU Pre-Accession Adviser ignores the 'naturalistic' responses and interprets twinning in terms of his exposure to the programme through his work. We can thus conclude that twinning is capable of being interpreted in a range of often very different ways by people, depending on their relationship to the object - whether it be a human twin, a town twinning initiative or an EC Twinning project.

Thus only those with experience (implicit knowledge) of the EC Twinning programme are able to describe it in terms appropriate to the meaning that the EC intends to convey. Therefore, it can be thought of as an 'arbitrary' sign - we know what it could mean, although this meaning could be multiple.

\footnotetext{
${ }^{3}$ See European Commission website http://europa.eu.int/comm/towntwinning/index en.html for more details on this concept.
} 
Interestingly, by adding project, twinning loses some of its arbitrariness, and becomes more explicit. Project is more explicit and relies less on convention to generate a precise meaning (and is thus more iconic).

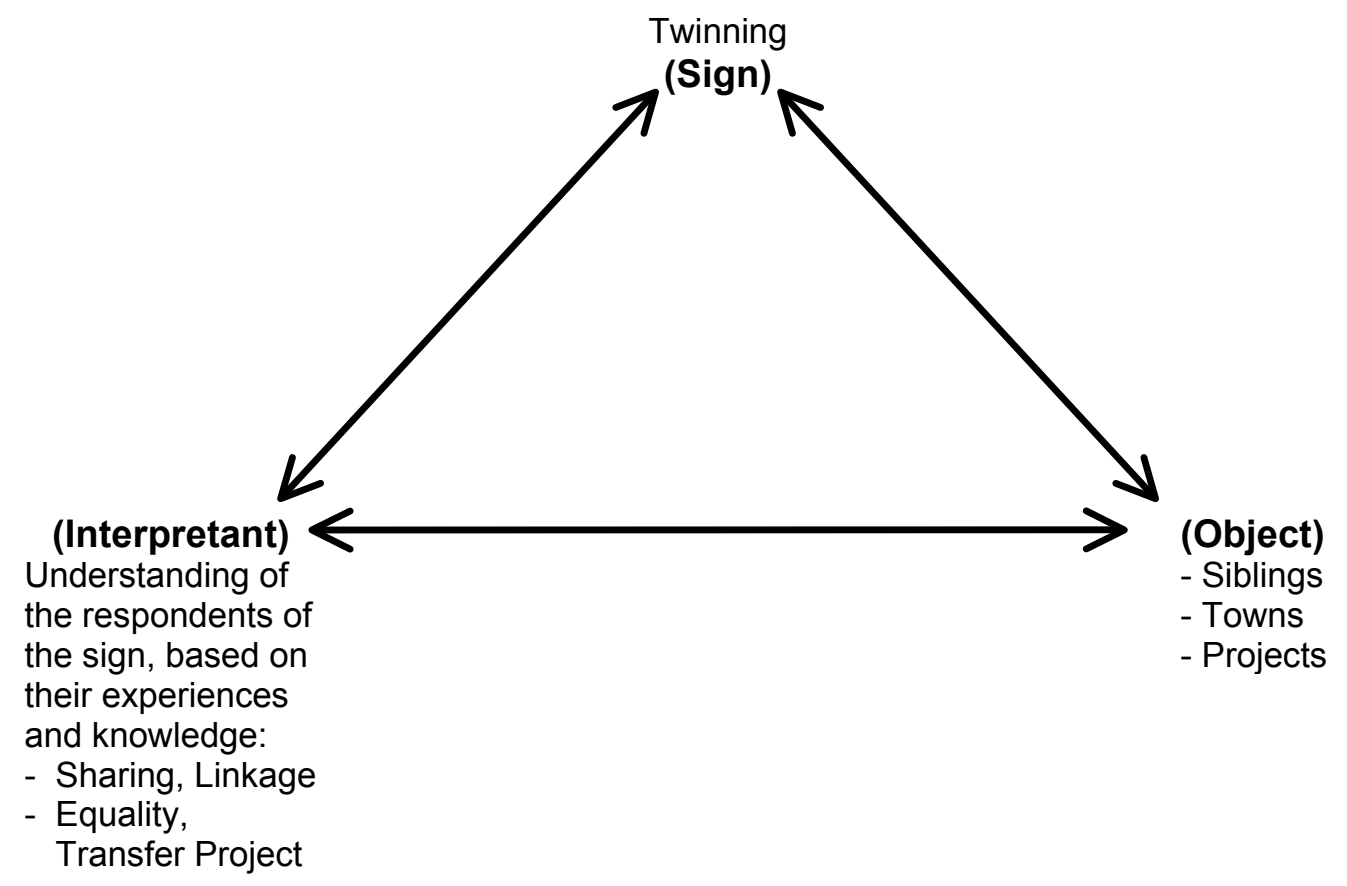

Figure 1. Peirce's model (Fiske, 1995) applied to the term 'twinning'.

\section{TWINNING AS A METAPHOR}

We can assert that in the context of EU programmes, twinning is a metaphor i.e. a vehicle to express the unfamiliar in terms that are familiar to the user (Fiske, 1995). As we have seen twinning resonates with the interpretant in a number of ways, dependent on its relation to the object. Nevertheless, it aroused a sense of familiarity among all those questioned in the survey, even those without any exposure to the Twinning programme itself. Asking the same question about technical assistance elicited a non-response from those without any knowledge of 'projects'. O'Connor and Seymour (1993) refer to a metaphor as a 'story of a journey from one place to the other' [present state $\rightarrow$ desired state]. In this regard, the European Commission has taken our interpretants on a journey away from the unfamiliar jargon of technical assistance to the more familiar, ambiguous, metaphoric twinning. The question to be asked here is why this journey is taking place and what are likely to be its outcomes?

\section{PRACTICAL IMPLICATIONS}

\section{Power relations and appropriate metaphors}

As mentioned in the introduction, the Twinning instrument largely supplanted the technical assistance (TA) project format that had been the standard approach of the Phare programme from 1993 to 1998. The EC was keen to improve the impact of its programme, which had suffered from implementation difficulties, low sustainability and a poor reputation among recipient institutions (Birker et al, 2000).

The creation of an instrument that links candidate country administrations (CCA) with those of existing EU member states (MS) represented a shift in the power relationships of the key actors in Phare the CCAs, MS administrations and the EC. Under TA, contractual power resided in the hands of the CC beneficiary institutions and the EC - a classic 'power over' model (Nelson \& Wright, 1995). Under TA, the CCAs could force consultants to implement projects with often very limited input from their own side and enforce contractual compliance if they felt dissatisfied with the delivery of assistance or its outputs. 
Now, with the introduction of Twinning, consultants were replaced by MS administrations - their collegial partners - and the CCAs were no longer able to manipulate the project delivery as overtly as had been the case with private consulting firms. This adjustment of the power balance ostensibly led to an improvement in buy-in from CCAs, although it also exposed the limited capacity of these administrations to participate effectively in project activities and their subsequent adoption (OMAS, 2001).

Twinning also brought about an erosion of the power of the EC. Under TA, the Commission enjoyed 'power over' both CCA and the contractor. However, with Twinning it was required to be far more circumspect in its dealings with the MS administrations and, as accession approached, with the CCs as well.

This change in power relations necessitated the utilization of a new vocabulary. Clearly, MS administrations were not contractors in any traditional sense. They would be unlikely to accept a subservient position vis-à-vis the CCAs. Likewise, candidate countries would be uncomfortable in a project dominated by a current MS. The adoption of the metaphor of twinning provided a comfortable solution - connotational, arbitrary, familiar and, crucially, vague. Its accompanying vocabulary also demonstrated these characteristics.

Table 1 illustrates how Twinning vocabulary represents a move away from the denotational terminology of TA towards something with greater connotational significance. Those terms at the top of the scale exhibit the widest variance in terms of connotational value, while there is minimal divergence of value at the bottom of the scale. In addition, if we look at some of the titles of other EU programmes, we can also see a similar pattern of behaviour in the choice of signs to designate EU programmes e.g. Equal, Access, Overture, Living Together. ${ }^{4}$

\begin{tabular}{lll}
\hline Term used in TA & Term used in Twinning & \\
\hline Technical assistance & Twinning & Connotational \\
Contracting parties & Twinning partners & \\
Contract & Covenant & \\
Contractor & Member State partner & \\
Consultant/Project Manager & Pre-Accession Adviser & \\
Contracting Authority & Candidate Country partner & Denotational \\
Consultant/Expert & Short-term technical expert & \\
Deliverables & Guaranteed results & \\
\hline
\end{tabular}

\section{A paradigm shift in project delivery?}

Although Twinning brought with it a change in power relations within the Phare programme and a new vocabulary, the actual mechanics of the delivery of assistance essentially remained intact. The MS administration replaced the consultancy firm and the pre-accession adviser (PAA) replaced the TA project manager, while the underlying structure of the instrument and the tasks required of the MS- to provide experts to CCAs for the purpose of know-how transfer - remained unchanged (See European Commission Twinning in Action, October 2001 pp 5-7 for a description of the Twinning mechanism).

Despite this, the European Commission continued to insist that Twinning and TA are fundamentally different instruments. The main guideline for management of the Twinning process, the EC's Twinning Manual, states; "Twinning is a joint project. It is not a one-way delivery of Technical Assistance from a Member State to a beneficiary country. It is a close partnership in which the specific commitment of the beneficiary, who is also the driving force behind the changes targeted, is vital" (European Commission 2004, p.5). However, external audits and the personal experiences of MS administration officials have found that, in practice, MS administrations end up with the lion's share of the work in the design and implementation phase of the projects (Birker et al 2000; EMS Consortium 2004). In a number of personal interviews conducted with MS Twinning staff (Insights gained from 2001 to 2004 during the $1^{\text {st }}$ author's work as an independent evaluator of the Phare programme in the Czech Republic

\footnotetext{
${ }^{4}$ For examples of these programmes see the following webpages europa.eu.int/comm/enlargement/ pas/phare/programmes/multi-bene/access $2000 . \mathrm{htm}$ http://europa.eu.int/comm/employment_social/equal/index_en.html http://europa.eu.int/comm/environment/emas/news/index_en.htm
} 
and then as Phare programme manager at the EC Delegation to Lithuania) project leaders often complained of the difficulty of getting the CCAs to take the project forward as a partnership, particularly during the covenant drafting and initial implementation phases. By contrast, CCA staff would see the partnership as an illusion, and work with the MS only to the extent that their limited capacities and commitment allowed - in essence as they had done under TA (EMS Consortium, 2004).

An even worse fate befalls the Pre-Accession Adviser (Since May 2004, the PAA has been renamed the Resident Twinning Adviser (RTA)). Those without prior knowledge of Twinning would, as we have seen from our survey, expect to be getting involved in a project based on equality and partnership. They would also, quite naturally, interpret their role as that of a counsellor and technical expert. However, instead of suggesting, informing and guiding on technical issues - as the term suggests and which is the basis upon which PAAs are recruited (The 2004 EC Twinning Manual describes the role of the RTA/PAA to be 'to provide technical advice and assist the administration or other public sector bodies in the beneficiary country in the context of a predetermined work plan.' p.5), the 'overwhelming expectation' is that the PAA will take on the role of project manager (EMS Consortium, 2004). Evaluators also found that in the majority of Twinning projects, 'facilitative and communication skills, in addition to political astuteness, are essential [for a PAA/RTA]', but often lacking (EMS Consortium, 2004, p.17). PAAs not surprisingly experience considerable dissonance at this state of affairs. Recruited as advisers, they find themselves 'unable to focus exclusively on advice, but almost invariably get drawn into project management' (OMAS Consortium 2001, p.10). This confusion of roles can (and does) result in the appointment of technical experts as PAAs who fundamentally misinterpret their role, who are poor managers and even worse communicators or facilitators, with inevitable consequences for their projects (Kowalski 2004). Thus we end up with twinning without twins, advisers who are not able to advise and projects without appropriately skilled managers.

\section{The future of Twinning}

A final point relates to the lifespan of Twinning. Although the 10 CCs joined the EU in May 2004, Twinning as an institution-building instrument looks set to remain central to the EC's enlargement strategy for the foreseeable future. Aside from the remaining $3 \mathrm{CCs}$ (Romania, Bulgaria, and Turkey) who have yet to enter the EU, Twinning is now being rolled out to the CARDS and MEDA countries (The CARDS programme covers the former Yugoslavia and Albania; MEDA focuses on countries on the southern and eastern Mediterranean rim), which means that a new group of administrations will become exposed to the metaphor of twinning and its accompanying ambiguous symbolism.

\section{CONCLUSION}

This article has explored the ambiguity contained in the terms used in the EU Twinning instrument and how, within the context of its delivery, this ambiguity potentially results in misunderstanding and confusion for the parties involved. We have seen that the apparently banal issue of terminology has, in fact, had a tangible influence on the preparation and implementation of projects that are large in both scope and financial impact.

Before drawing some conclusions from these findings, it is worthwhile to briefly place two caveats against our analysis. Firstly, interviews with Twinning project staff indicate that the initial confusion and subsequent difficulties in project delivery generally disappear over time, as both sides get used to the reality on the ground and re-attune their interpretants. Also, PAAs doing the job for a second time were under no illusions as to the task awaiting them - project manager first, adviser second. Oddly the EC doesn't permit individuals to be appointed more than twice as PAA, which means that there is always a cadre of new PAAs waiting to be confused and surprised by Twinning.

Secondly, the EC has increased the provision of training for PAAs and their CCA counterparts noticeably since introduction of Twinning - from none in 1998 to two full days in 2004, so the potential for misunderstanding of the purpose of Twinning and the PAA's role has, theoretically, been reduced. However, the training focuses mainly on the mechanics of the Twinning process and does not impart skills such as project management or facilitation techniques (EMS Consortium, 2004). Thus, whether the recruitment process has discovered people capable of doing a PAA's job, or the training adequately equips them for this task remains open to question (EMS Consortium, 2004). 


\section{SOLUTIONS}

How is it possible to sort out some of the misunderstandings that result from Twinning's terminology? To find an answer, let us return to Peirce's triangular model.

The first point of the triangle is the sign - the terminology of Twinning. We can consider changing it to overcome potential ambiguity, by making it more explicit and denotational. While this is an apparently simple solution, one has to question whether this would bring about any qualitative improvement in the delivery of the programme itself. It would probably help sort out the short term misunderstandings of the parties involved, but the underlying inadequacies of the instrument would remain untouched.

The second point of the triangle is that of the interpretant - what is understood by the terminology. One practical solution directed here would be to attune the interpretants of the users, either through the further provision of training and accompanying materials, or through practical experience of the project. Certainly, the current training structure presents a good starting point for this. However, such training provision would require significant restructuring the $\mathrm{EC}$, in terms of its scope and content, if it is to adequately prepare both MS and CC staff for the task ahead. Also, the interpretant of the EC Twinning unit at the Enlargement Directorate would benefit from re-attuning in regard to PAA's job descriptions. Rather than looking for technical advisers, prioritising project management and communication skills of PAAs would help clarify this particular ambiguity, ensure that Twinning projects run more smoothly and that the recruited PAAs are enabled to professionally discharge their highly complex duties.

The final point of Peirce's model is the object - the programme itself. And it is perhaps here that we reach the heart of the whole issue. Instead of concealing the nature of the Twinning instrument with ambiguous vocabulary, it may be more appropriate to bring the programme itself closer to the established meaning of the sign, as indicated by our survey i.e. by strengthening its partnership element, and developing its mutuality and balance of responsibility. Certainly we can conclude from the findings of independent experts that many of the weaknesses in the Twinning programme stem from this lack of shared responsibility. By addressing this core problem we would not only avoid ambiguity in the significance of Twinning, we would much improve its effectiveness as an instrument for preparing Phare countries for membership in the EU.

\section{REFERENCES}

Birker, E. Cooper, C. Molander, P. Pochard, M. 2000. Report on an Assessment of the Twinning Instrument under Phare European Commission, accessed at http://europa.eu.int/comm/enlargement/pas/twinning/pdf/assesm july.pdf on 20/11/2004.

Chandler, D. 2002. Semiotics - The Basics, Routledge, London.

EMS Consortium 2004. From Pre-Accession to Accession - Thematic Evaluation of Second-Generation Twinning. European Commission,. Accessed at http://europa.eu.int/comm/enlargement/phare evaluation pdf/fv zz twi 03057.pdf on 21/11/2004.

European Commission. 2001. Twinning in Action, October. Accessed at http://europa.eu.int/comm/enlargement/pas/twinning/pdf/twinning en.pdf on 22/11/2004.

European Commission. 2004 Institution Building in the Framework of European Union Policies - A Reference Manual on 'Twinning' Projects. Accessed at http://europa.eu.int/comm/enlargement/pas/twinning/pdf/manual 2004_en.pdf on 0/11/2004

Fiske, J. 1995. Introduction to Communication Studies ( $2^{\text {nd }}$ edition), Routledge, London

Kowalski, R. 2004. Development - Paradox, paralysis and praxis. Protosociology_20, 390 - 411.

Nelson, N. \& Wright, S. 1995. Power and Participatory Development, Intermediate Technology Publications, London.

O’Connor, J and Seymour, J. 1993. Introducing Neuro-Linguistic Programming, Aquarian Press/Thorsons, London.

OMAS Consortium 2001 Assessment of the European Union Phare Programmes (Multi-Country) Accessed at http://europa.eu.int/comm/enlargement/phare evaluation_pdf/interim_s_zz_eur_01006_fv.pdf on 20/11/2004. 
